\title{
KARAKTERISTIK VISUAL GAPURA WRINGIN LAWANG PADA GAPURA DI PERBATASAN KOTA MALANG
}

\section{Adrian Widisono}

Magister Arsitektur Lingkungan Binaan, Jurusan Arsitektur, Universitas Brawijaya, Malang awidisono@gmail.com

\section{Yusfan Adeputera Yusran*}

Jurusan Arsitektur, Universitas Brawijaya, Malang

yusfan@ub.ac.id ('email korespondensi)

\section{Antariksa}

Guru Besar Jurusan Arsitektur, Universitas Brawijaya, Malang

mr.antariksa@gmail.com

\begin{abstract}
Abstrak
Zaman Kerajaan Majapahit merupakan cikal bakal munculnya Gapura. Pada zaman tersebut gapura memiliki fungsi sebagai pintu masuk menuju kerajaan. Pergeseran masa menunjukkan pergeseran fungsi terhadap gapura yang saat ini menjadi penanda menuju masuknya suatu kota termasuk Kota Malang. Gapura perbatasan pintu masuk di Kota Malang teridentifikasi memiliki karakter yang mirip dengan salah satu candi peninggalan Majapahit yaitu Gapura Wringin Lawang yang terletak di Mojokerto, Jawa Timur. Studi ini bertujuan untuk memvisualisasikan kesesuaian karakter visual gapura perbatasan di sebelah utara, barat, timur dan selatan Kota Malang dengan Gapura Wringin Lawang. Penyandingan empat gapura perbatasan dengan Gapura Wringin Lawang dianalisis dengan mengidentifikasi elemen desain, prinsip desain, dan ciri fisik gapura. Hasil penelitian ini menunjukkan kesesuaian secara visual pada gapura pintu masuk di Kota Malang dengan Gapura Wringin Lawang. Kesesuaian elemen desain meliputi: garis, bentuk, massa, ruang, dan tekstur. Pada prinsip desain persamaan terdapat pada keseimbangan, kontras dan penekanan, bentuk, koneksi, makna, simbol, dan citra, pola, skala dan proporsi, ritme dan variasi. Pada bagian ciri fisik terdapat pula kesamaan yaitu bagian kepala, badan, dan kaki gapura
\end{abstract}

Kata-Kata Kunci: karakteristik, visual, gapura, penanda, batas kota

\section{VISUAL CHARACTERISTIC OF GAPURA WRINGIN LAWANG ON THE GATES OF MALANG CITY'S BOUNDARY}

\begin{abstract}
The era of the Majapahit Kingdom was the forerunner to the appearance of the Gapura (gate). At that time, the Gapura was built as the entrance to the kingdom. Over time, the function has shifted as a signifier of a city boundary, as found in Malang City. The boundary gate of Malang City identified has a character similar to the Majapahit heritage temples, namely the Wringin Lawang Gate located in Mojokerto, East Java. This study aims to visualize the suitability of the visual characteristics of the border gate in the northern, eastern, western and southern of Malang City with the Wringin Lawang
\end{abstract}


Gate. The comparison of the four gates with Wringin Lawang Gate was analyzed by identifying its elements, principles, and physical characteristics. The results of this study indicate the visual suitability. The suitability of elements found in lines, shapes, mass, space, and textures. On the principle of design, equality identified in balance, contrast and emphasis, form, connection, meaning, symbol, and image, pattern, scale and proportion, rhythm and variation. While in the physical characteristics, there are also similarities in the part of the head, body, and leg of the gate.

Keywords: characteristics, visual, gate, signifier, city's boundary

\section{Pendahuluan}

Gapura memiliki arti dari bahasa Sansekerta, yaitu "Gopura" yang berarti pintu gerbang (Suwarna, 1987). Gapura secara umum sebagai istilah bagi pintu masuk candi, rumah bangsawan, keraton, desa dan negara (Alston, 1964). Gapura merupakan salah satu prasasti peninggalan kerajaan majapahit yang bercorak hindu. Salah satu contoh gapura yang masih ada sekarang yaitu Gapura Wringin Lawang yang masih berdiri sejak abad ke-14 yang berlokasi di Desa Jatipasar, Kecamatan Trowulan, Kabupaten Mojokerto, Provinsi Jawa Timur.

Secara fisik Gapura Wringin Lawang memiliki bentuk seperti candi yang dibelah dua secara sempurna sehingga memiliki keseimbangan simetris yang banyak ditemukan di Pulau Jawa, Bali dan Lombok (Sosial, et al., 2017). Pada zaman Majapahit gapura dimaknai sebagai pintu masuk menuju kerajaan sehingga area ini dapat diklasifikasikan sebagai area profan sedangkan area dalam kerajaan sebagai area yang sakral, artinya Gapura pada zaman itu tidak digunakan sebagai penanda saja melainkan juga sebagai pembeda zonasi ruang. Ciri dari gapura ini, yaitu pada bagian atap terbuka (gapura belah), pada bagian badan dan kaki tidak dilengkapi ornamentasi melainkan garis horisontal yang dominan (Yudoseputro, 2008).

Saat ini gapura sering kali terlihat sebagai penanda batas antar kota khususnya pada objek studi, yaitu di Kota Malang. Terdapat perubahan fungsi gapura yang dulunya sebagai pintu gerbang masuk kerajaan dan kini sebagai penanda batas antar kota. Melihat fenomena tersebut, studi ini bertujuan untuk mengetahui karakteristik visual gapura-gapura yang menjadi penanda batas Kota Malang dengan Gapura Wringin Lawang. Gapura penanda batas kota ini terletak di sebelah utara, barat, timur dan selatan Kota Malang.

Pada pembahasan karakter visual dapat dipahami sebagai identitas yang melekat pada bangunan yang dapat membedakan antara bangunan satu dengan yang lainnya. Karakter visual tidak lepas dari elemen dan prinsip desain. Elemen desain menurut Dietrich (2006) terdiri dari material, warna, garis, bentuk, massa, ruang, dan tekstur. Karakter visual didapatkan secara keseluruhan dengan prinsip desain berupa: keseimbangan, kontras, bentuk, koneksi, penekanan, pengelompokan, makna, simbol, citra, pola, penempatan/jarak, proporsi, ritme, skala, kesatuan, variasi (Mohan, 2006; Dietrich, 2006).

Perbedaan masa menjadikan gapura masa kini menyesuaikan aspek visualnya menjadi mengkini sehingga perlu dianalisis terkait aspek visual gapura peninggalan Kerajaan Majapahit, yaitu Gapura Wringin Lawang dengan gapura perbatasan yang ada di Kota Malang.

\section{Kajian Pustaka}

\section{Gapura}

Indonesia hakikatnya memiliki tradisi arsitektur yang kuat dan unggul. Hal tersebut tercermin dari wujud arsitekturalnya. Wujud arsitektur yang beragam dan dinamis merupakan bagian dari tradisi arsitektur. Salah satu wujud jejak arsitektur Indonesia di era Klasik-Hindu-Buddha Kerajaan Majapahit 
yang ada sampai saat ini yaitu bangunan pemujaan kuil yang dikenal dengan "candi". Klasifikasi bangunan kuil (candi) dikategorikan ke dalam klasifikasi grand design tradition yang mempresentasikan high style, main culture, power and good tastes of pattern and designer (Rapoport, 1978). Oleh karena itu, candi dapat dimasukkan ke dalam hasil suatu kebudayaan pada masanya.

Berdasarkan tipologi arsitektur candi terdapat empat tipe candi, tipe tersebut yaitu Menara, berundak, kolam/petirtan, dan gua (Rahadian, 2018). Tipe Menara biasanya berbentuk candi seperti Candi Prambanan, Sewu, dan Gedongsongo. Tipe Berundak merupakan bangunan pepunden yang disusun berundak seperti candi di lereng Penanggunangan, Lawu, dan Borobudur. Tipe Kolam/Pertirtan merupakan bangunan yang menyerupai kolam seperti Candi Tikus dan Candi Penataran. Tipe Gua dapat dikaitkan dengan fungsi ritual ataupun meditasi contohnya Gua Selomangleng kediri, Gua Gajah, dan Gua Sentono. Selain tipe tersebut terdapat pula candi berbentuk gapura/pintu gerbang, yaitu gapura panduraksa dan bentar/belah.

Gapura biasanya berfungsi sebagai pintu gerbang menuju kerajaan yang memisahkan area sakral (area dalam kerajaan) dan profan (area luar kerajaan), seperti yang terdapat pada Gapura Wringin Lawang. Secara fisik, vertikalitas gapura terdiri dari kepala-badan-kaki atau kepala-tubuh-alas (Prasodjo \& Degroot, 2013). Bagian Alas atau Kaki dapat berbentuk persegi/bujursangkar, berketinggian menyerupai batur dan dicapai melalui tangga. Bagian Tengah atau Tubuh candi pada umumnya berdimensi lebih kecil dari alasnya, pada bagian badan berbentuk kubus atau silinder. Bagian Atas atau Atap Candi terdiri dari susunan tingkatan (pada umumnya tiga tingkatan) yang semakin mengecil ke atas, diakhiri dengan mahkota.

\section{Karakter visual}

Karakter berarti salah satu fitur yang membedakan antar individu. Karakter juga dapat dipahami sebagai ciri khas yang dapat membedakan individu atau kelompok satu dengan yang lainnya (Adenan, Budi, \& Wibowo, 2012). Secara keseluruhan karakter visual dapat dilihat melalui elemen fisik dari bangunan (Berry, 1980). Elemen fisik pada gapura tersebut dapat diketahui melalui identifikasi terhadap prinsip dan elemen desain pada bagian kepala-badan-kaki untuk mengeksplorasi karakter visualnya. Prinsip desain menurut Mohan (2006) dan Dietrich (2006) dapat meliputi; keseimbangan (simetris dan asimetris), kontras (ukuran, bentuk, massa), bentuk (geometris), koneksi (koneksi menuju suatu tempat, koneksi interior-eksterior), penekanan (warna, ukuran, bentuk), pengelompokan, makna (arti tertentu), simbol, citra (presepsi dan konseptual), pola, penempatan/jarak, proporsi, ritme, skala (besar dan kecil), kesatuan, variasi. Elemen desain menurut Dietrich (2006) meliputi; material, warna, garis, bentuk, massa, ruang, tekstur (halus dan kasar).

\section{Metode}

Studi ini menggunakan metode deskriptif analitik untuk mengetahui karakteristik visual pada gapura gerbang pintu masuk yang berada di utara, selatan, timur, dan barat Kota Malang. Studi ini didahului dengan melakukan observasi lapangan pada gapura yang menjadi objek penelitian untuk mengidentifikasi elemen dan karakter visualnya. Hasil identifkasi ini kemudian dianalisis dengan parameter variabel elemen visual Mohan (2006) dan Dietrich (2006) (Tabel 1 dan Tabel 2), kemudian disandingkan dengan Gapura Wringin Lawang. Data primer berupa dokumentasi empat gapura di perbatasan Kota Malang di redraw untuk memudahkan tahap analisis. Data sekunder menggunakan sumber primer berupa jurnal untuk menentukan variabel dan membantu dalam tahap analisis karakteristik visual gapura perbatasan yang ada di Kota Malang. Selain itu, analisis dilakukan terkait dengan ciri fisik gapura. 
Tabel 1. Variabel Penelitian Karakter Visual (Prinsip Desain)

\begin{tabular}{|c|c|c|}
\hline No. & Variabel & Definisi \\
\hline 2. & Kontras & $\begin{array}{l}\text { Penggunaan kontras melalui: ukuran, bentuk dan massa, warna (hue, nilai, intensitas), tekstur dan pola, } \\
\text { pencahayaan, penempatan atau kedekatan dalam desain. }\end{array}$ \\
\hline 3. & Bentuk & $\begin{array}{l}\text { Penggunaan berbagai bentuk, ukuran, skala dan karakteristik permukaan akan memberikan persepsi berat atau } \\
\text { ringan yang terkait dengan komposisi. }\end{array}$ \\
\hline 4. & Koneksi & $\begin{array}{l}\text { Desain arsitektur sebagai sarana merakit bagian-bagian yang berbeda menggunakan prinsip koneksi untuk } \\
\text { menciptakan rasa keseluruhan }\end{array}$ \\
\hline 6. & Pengelompokan & $\begin{array}{l}\text { Proses pengelompokan mengacu pada perakitan bagian-bagian yang berbeda untuk menciptakan "bagian" atau } \\
\text { bagian yang lebih besar dalam seluruh komposisi }\end{array}$ \\
\hline 7. & Makna & Makna adalah prinsip desain yang terkait erat dengan prinsip-prinsip simbolisme dan citra \\
\hline 8. & Simbol & $\begin{array}{l}\text { Penggunaan simbolisme adalah komponen penting dalam membangun sarana dan metode di mana desain } \\
\text { arsitektur dibaca dan dipahami }\end{array}$ \\
\hline 9. & Citra & $\begin{array}{l}\text { Citra dalam desain arsitektur melibatkan penggunaan simbolisme untuk menciptakan gambar yang } \\
\text { mengandung makna relatif terhadap solusi desain }\end{array}$ \\
\hline 12. & Proporsi & Proporsi berkaitan dengan persamaan atau rasio yang dirasakan antara elemen desain arsitektur \\
\hline 13. & Ritme & $\begin{array}{l}\text { Penggunaan ritme dalam desain arsitektur menyiratkan respon melodi yang dimasukkan ke dalam solusi yang } \\
\text { dibangun }\end{array}$ \\
\hline 14. & Skala & Skala dalam desain arsitektur berkaitan erat dengan perkembangan proporsional \\
\hline 15. & Kesatuan & $\begin{array}{l}\text { Kesatuan dapat dicapai dengan hubungan antara unsur-unsur yang berbeda seperti: } \\
\text { - pengulangan bentuk, pola, tekstur dan ukuran yang berbeda } \\
\text { - keharmonisan visual dan tekstur melalui penggunaan warna, bahan dan bentuk } \\
\text { - penggunaan batasan (fisik atau tersirat) }\end{array}$ \\
\hline 16. & Variasi & $\begin{array}{l}\text { Ragam memberikan minat visual dalam elemen terpadu melalui penggunaan teknik yang berbeda termasuk } \\
\text { bentuk, ukuran, warna, tekstur, material, dan pola }\end{array}$ \\
\hline
\end{tabular}

Sumber: Mohan, 2006; Dietrich, 2006

Tabel 2. Sub-Variabel Penelitian Karakter Visual (Elemen Desain)

\begin{tabular}{|c|c|c|}
\hline No. & Variabel & Definisi \\
\hline 1. & Material & Bahan penyusun dari objek amatan \\
\hline 2. & Warna & Unsur warna yang melekat pada objek amatan \\
\hline 3. & Garis & Penggunaan garis penyusun bentuk dasar objek (horisontal, vertikal, dan diagonal) \\
\hline 4. & Bentuk & Bentuk dasar atau garis terluar objek amatan (persegi, segitiga, dan lingkaran) \\
\hline 5. & Massa & $\begin{array}{l}\text { Bentuk tiga dimensional meliputi: } \\
\text { - Massa geometris: kubus, limasan, dan bola. } \\
\text { - Massa natural: gabungan massa beberapa massa geometris. } \\
\text { - Massa abstrak : tidak teridentifikasi massa geometrisnya } \\
\text { - Massa nonobjektif: memiliki bentuk ekstrim. }\end{array}$ \\
\hline 6. & Ruang & Menciptakan suatu ruang atau batas \\
\hline 7. & Tekstur & Tampilan permukaan \\
\hline
\end{tabular}

Sumber: Dietrich, 2006

\section{Hasil dan Pembahasan}

Objek studi berada di Kota Malang yang memiliki luas wilayah 145,28 km². Di setiap titik masuk perbatasan wilayah yang ada di Kota Malang memiliki gapura sebagai penanda kawasan.

\section{Identifikasi Objek Penelitian}

Terdapat empat gapura pada objek studi yang diteliti. Objek tersebut terletak di sebelah utara, selatan, barat, dan timur perbatasan Kota Malang (Gambar 1). Obyek ini dipilih dengan pertimbangan bahwa di setiap titik ini terdapat gerbang yang representatif terhadap objek pembanding, yaitu Gapura 
Wringin Lawang. Selain itu, gerbang-gerbang ini merupakan jalur arteri utama untuk masuk ke dalam kawasan Kota Malang.

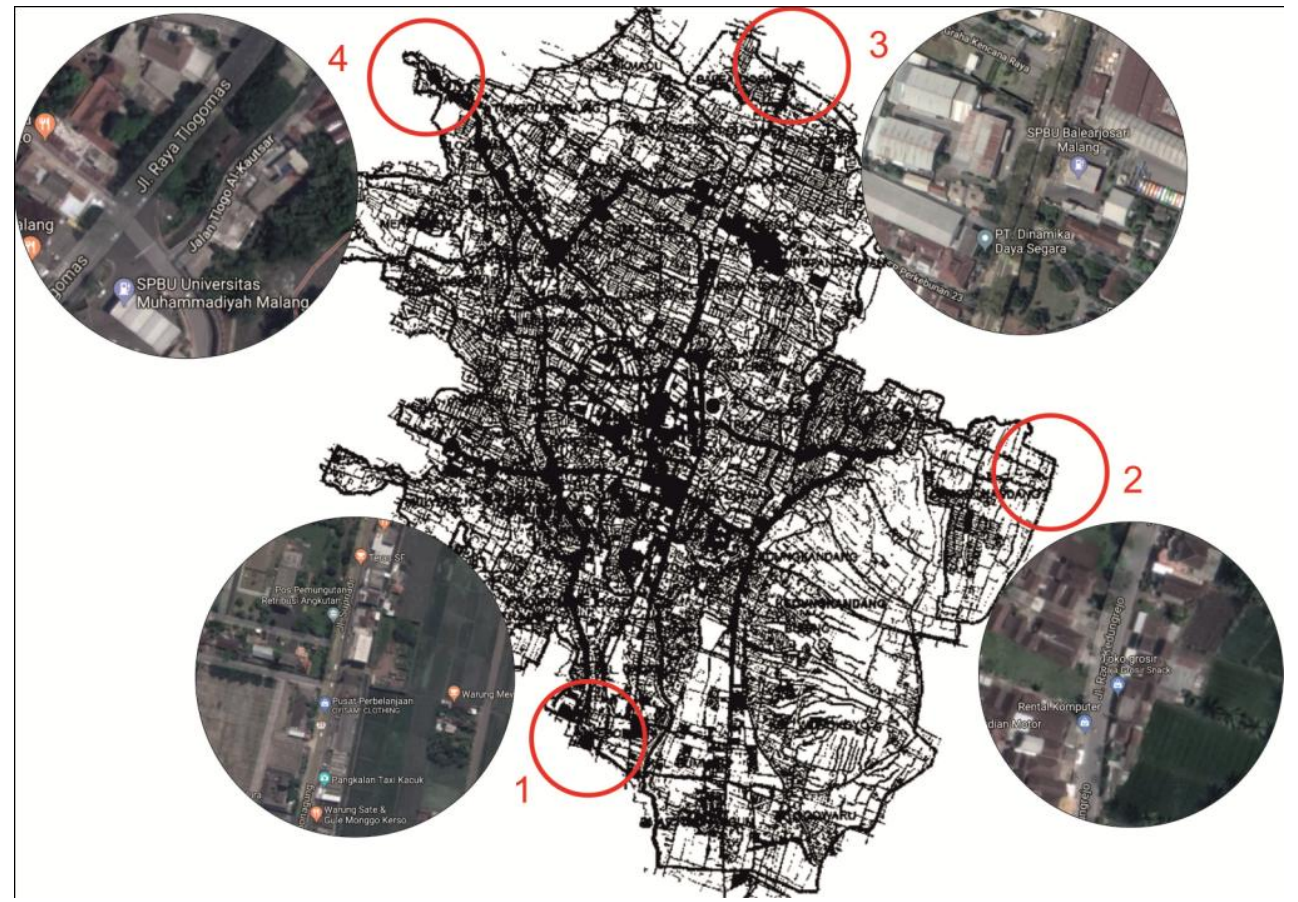

Gambar 1. Keyplan Objek Penelitian di perbatasan Kota Malang Sumber: Penulis, 2018

Tabel 3. Objek Penelitian

\begin{tabular}{|c|c|c|c|}
\hline Obyek Penelitian & Lokasi & Batas & Penjelasan \\
\hline Gapura 1 & $\begin{array}{l}\text { Jalan Nasional, Kecamatan } \\
\text { Pakisaji, Kabupaten Malang. }\end{array}$ & $\frac{\Xi}{\frac{\pi}{\pi}}$ & $\begin{array}{l}\text { Gapura ini menghubungkan antara Kecamatan } \\
\text { Pakisaji Kabupaten Malang dengan Kota Malang } \\
\text { yang ada di sebelah Selatan. Letak gapura } 1 \text { ini } \\
\text { dekat dengan pabrik gula Kebonagung Malang. }\end{array}$ \\
\hline \multicolumn{4}{|l|}{ Gapura 2} \\
\hline & $\begin{array}{l}\text { Jalan Raya Kedungrejo, } \\
\text { Kecamatan Pakis, Kabupaten } \\
\text { Malang. }\end{array}$ & $\stackrel{\Xi}{\Xi}$ & $\begin{array}{l}\text { Gapura ini menghubungkan antara Kecamatan } \\
\text { Pakisaji Kabupaten Malang dengan Kota Malang } \\
\text { yang ada di sebelah Timur }\end{array}$ \\
\hline \multicolumn{4}{|l|}{ Gapura 3} \\
\hline & $\begin{array}{l}\text { Jalan Raya Malang-Gempol } \\
\text { Kelurahan Balearjosari, } \\
\text { Kecamatan Blimbing, Kota } \\
\text { Malang. }\end{array}$ & 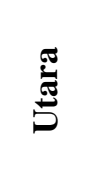 & $\begin{array}{l}\text { Gapura ini menghubungkan antara Kecamatan } \\
\text { Singosari Kabupaten Malang dengan Kota Malang } \\
\text { yang ada di sebelah Utara. }\end{array}$ \\
\hline
\end{tabular}


Langkau Betang, Vol. 5, No. 2, Tahun 2018

\begin{tabular}{lll} 
Jalan Raya Tlogomas, & \\
Kecamatan Lowokwaru, Kota & & Gapura ini menghubungkan antara Jalan Raya \\
Malang. & & $\begin{array}{l}\text { Tlogomas dengan Jalan Raya Sengkaling dimana } \\
\text { akan menuju Kota Batu yang ada di sebelah Barat. }\end{array}$ \\
\hline
\end{tabular}

Sumber: Penulis, 2018 


\section{Analisis Objek Penelitian}

\section{A. Analisis Elemen Desain}

Karakter visual dari gapura tidak lepas dari asas desain dan prinsip desain. Berikut ini analisis penyandingan elemen desain dan prinsip desain antara empat gapura di Malang dengan Gapura Wringin Lawang (Tabel 4).

Tabel 4. Analisis Terhadap Elemen Desain

\begin{tabular}{|c|c|c|c|c|c|c|c|}
\hline Objek & Material & Warna & Garis & Bentuk & Massa & Ruang & Tekstur \\
\hline $\begin{array}{c}\text { Gapura Wringin } \\
\text { Lawang }\end{array}$ & $\begin{array}{l}\text { Material } \\
\text { menggunakan } \\
\text { bata merah } \\
\text { pada seluruh } \\
\text { bagian candi. }\end{array}$ & $\begin{array}{l}\text { Warna candi } \\
\text { dominan } \\
\text { merah } \\
\text { kecoklatan } \\
\text { yang muncul } \\
\text { karena } \\
\text { penggunaan } \\
\text { bata merah. }\end{array}$ & $\begin{array}{l}\text { Garis yang } \\
\text { digunakan dominan } \\
\text { garis vertikal untuk } \\
\text { memunculkan kesan } \\
\text { monumental. Selain } \\
\text { itu terdapat garis } \\
\text { horisontal dan } \\
\text { diagonal } \\
\text { memunculkan kesan } \\
\text { dinamis. }\end{array}$ & $\begin{array}{l}\text { Bentuk dasar berupa } \\
\text { trapesium yang } \\
\text { dibelah menjadi dua. }\end{array}$ & $\begin{array}{l}\text { Pawa Gapura Wringin } \\
\text { Lawang memiliki } \\
\text { massa geometris } \\
\text { berupa limasan. }\end{array}$ & $\begin{array}{l}\text { Gapura Wringin } \\
\text { Lawang } \\
\text { menciptakan ruang } \\
\text { profan pada bagian } \\
\text { luar dan sakral pada } \\
\text { bagian dalam } \\
\text { kerajaan. }\end{array}$ & $\begin{array}{l}\text { Tekstur yang } \\
\text { ditimbulkan } \\
\text { karena } \\
\text { penggunaan } \\
\text { material bata } \\
\text { merah yaitu } \\
\text { memunculkan } \\
\text { tekstur kasar. }\end{array}$ \\
\hline Gapura 1 & $\begin{array}{l}\text { Pada gapura } 1 \\
\text { menggunakan } \\
\text { batu alam }\end{array}$ & $\begin{array}{l}\text { Warna pada } \\
\text { gapura yaitu } \\
\text { hitam yang } \\
\text { muncul } \\
\text { karena } \\
\text { penggunaan } \\
\text { material batu } \\
\text { alam }\end{array}$ & $\begin{array}{l} \\
\text { Garis yang } \\
\text { digunakan vertikal } \\
\text { dan horisontal. } \\
\text { Perulangan garis } \\
\text { horisontal untuk } \\
\text { menyeimbangkan } \\
\text { garis vertikal yang } \\
\text { dominan }\end{array}$ & $\begin{array}{l}\text { Bentuk dasar berupa } \\
\text { trapesium yang } \\
\text { dibelah menjadi dua. }\end{array}$ & $\begin{array}{l}\text { Pada gapura } 1 \\
\text { memiliki massa } \\
\text { geometris sama } \\
\text { dengan Gapura } \\
\text { Wringin Lawang } \\
\text { berupa limasan }\end{array}$ & $\begin{array}{l}\text { Gapura } 1 \\
\text { menciptakan batas } \\
\text { karena fungsi dari } \\
\text { gapura ini yaitu } \\
\text { batas antar wilayah. }\end{array}$ & $\begin{array}{l}\text { Tekstur yang } \\
\text { muncul yaitu } \\
\text { kasar yang } \\
\text { muncul karena } \\
\text { penggunaan } \\
\text { material bata } \\
\text { hitam. }\end{array}$ \\
\hline
\end{tabular}




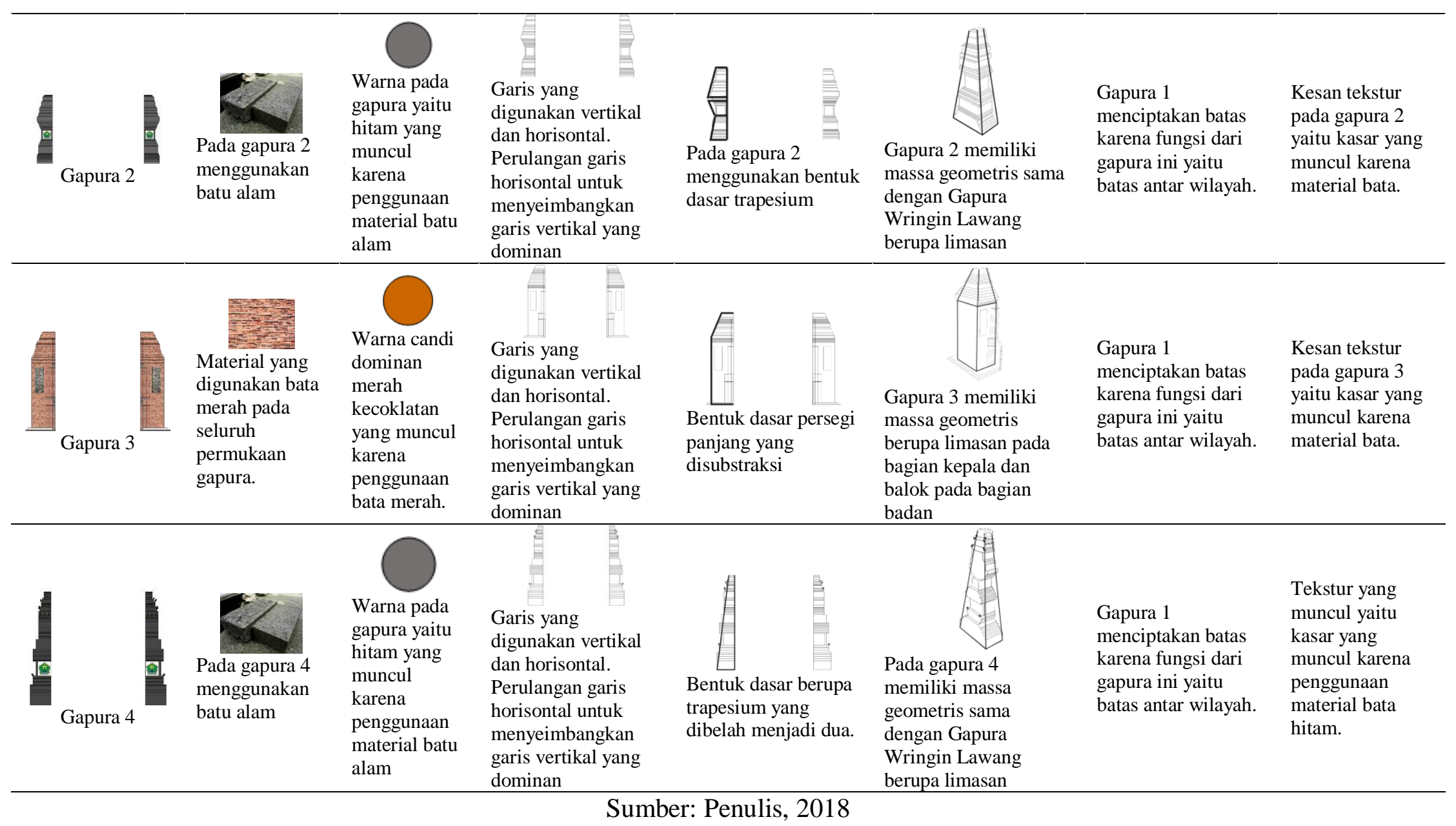

Hasil analisis terhadap elemen desain dan prinsip desain menunjukkan bahwa terdapat kesamaan antara Gapura Wringin Lawang dengan Gapura Perbatasan di Kota Malang. Persamaan pada elemen desain meliputi garis, bentuk, massa, ruang, dan tekstur. Garis yang digunakan pada gapur, yaitu memiliki dominasi garis vertikal yang memunculkan kesan monumental, selain itu terdapat garis horizontal pada kepala, badan, dan, kaki dari gapura. Bentuk keseluruan dari gapura menggunakan bentuk dasar trapesium dikombinasi dengan persegi panjang. Massa pada gapura keseluruhan menggunakan massa geometris limasan. Tekstur yang muncul akibat material bata merah dan batu alam adalah tekstur kasar. 


\section{B. Analisis Prinsip Desain}

Tabel 5. Analisis Terhadap Prinsip Desain

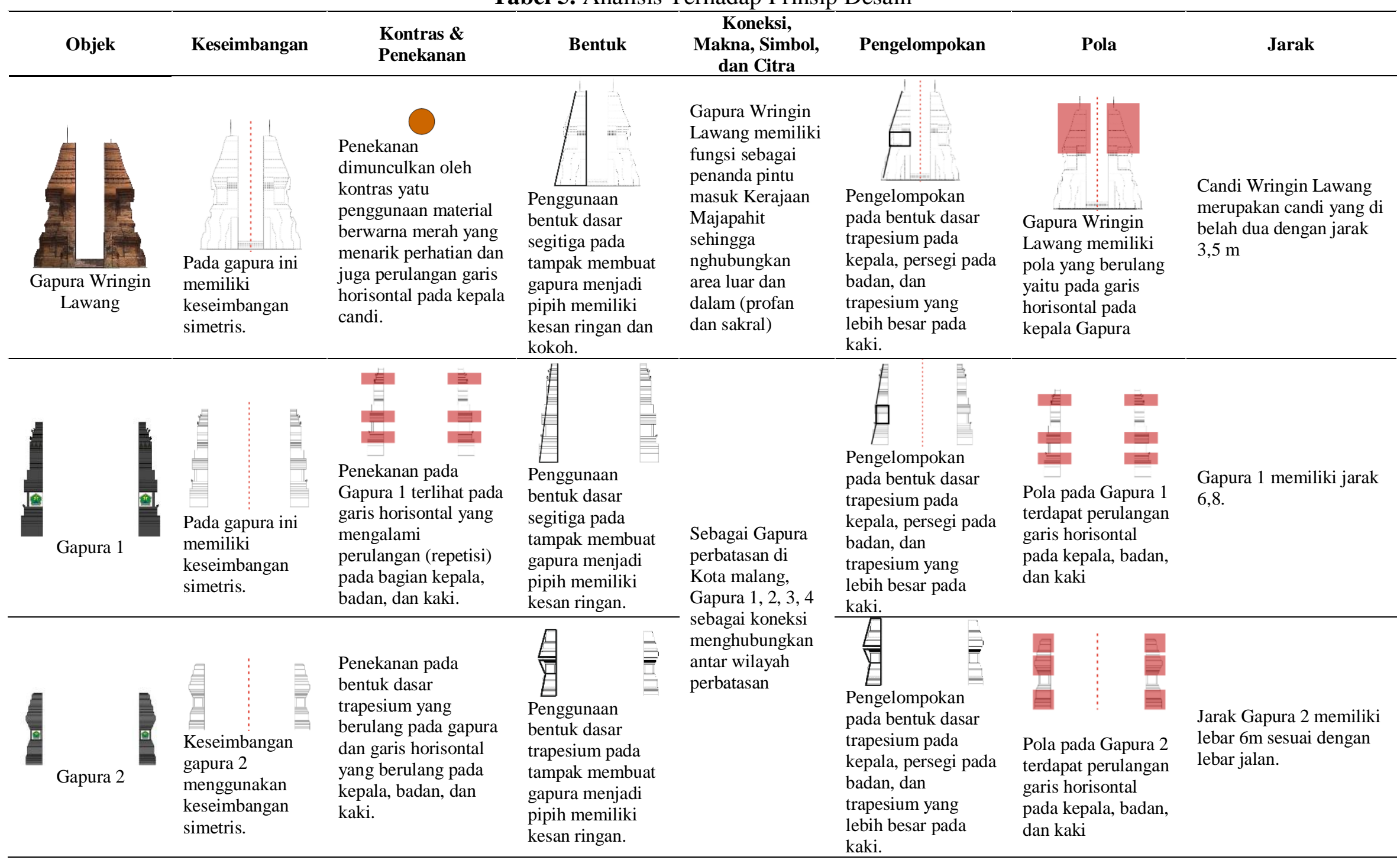




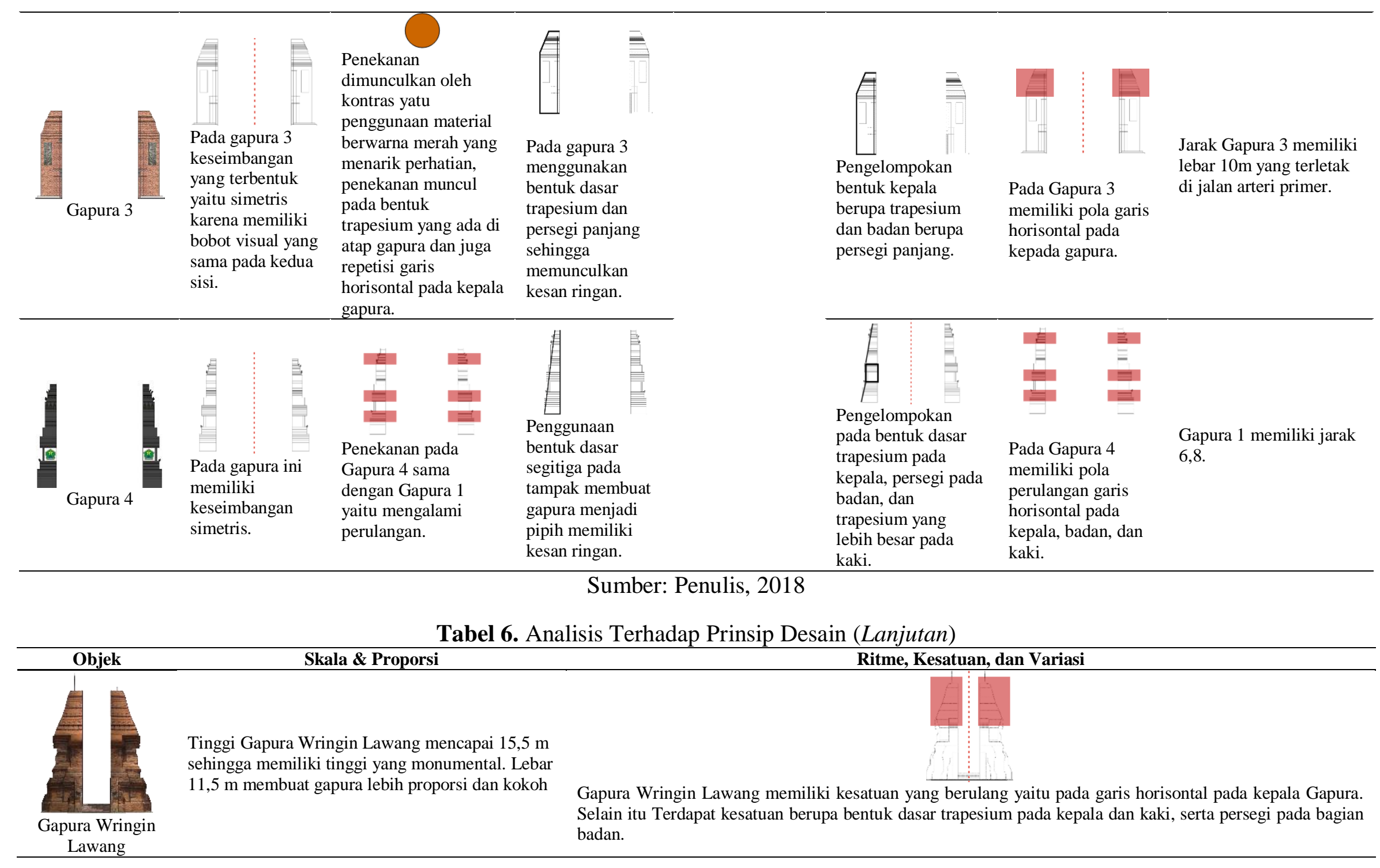




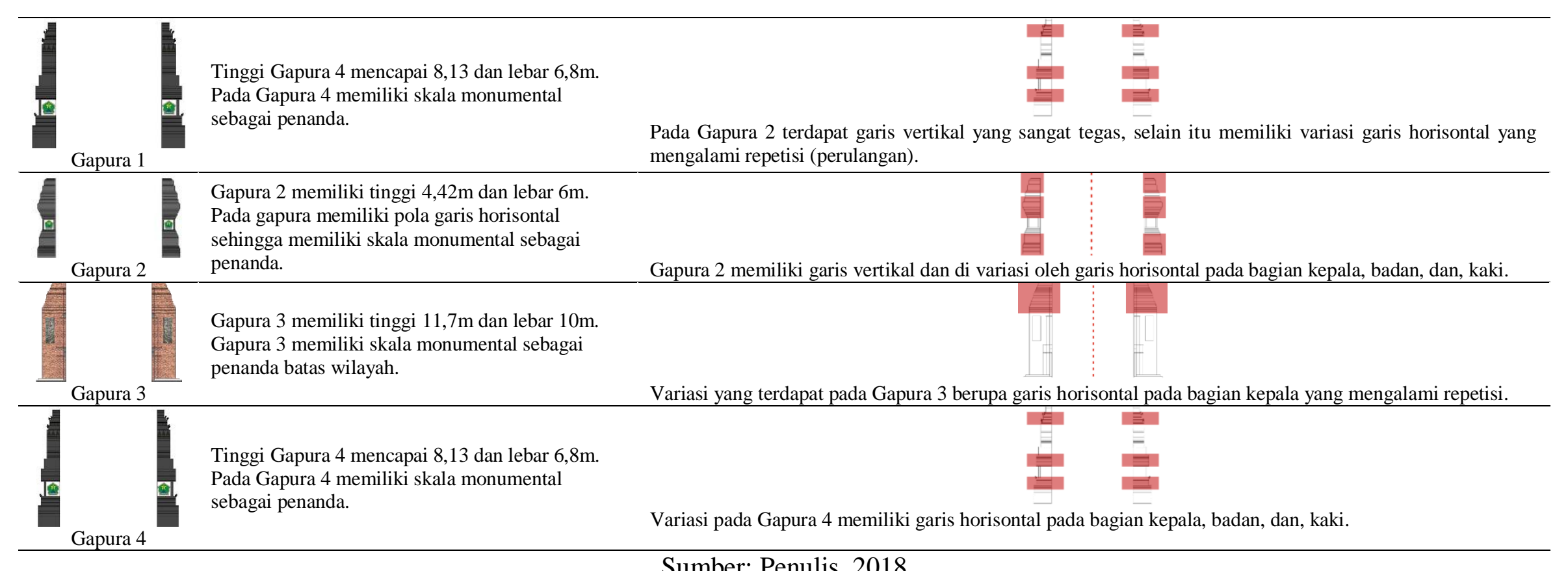

\section{Sumber: Penulis, 2018}

Kesamaan pada prinsip desain meliputi keseimbangan, kontras dan penekanan, bentuk, koneksi, makna, simbol, dan citra, pola, skala dan proporsi, ritme dan variasi. Keseimbangan yang digunakan pada seluruh gapura yaitu keseimbangan simetris karena pada sisi kanan dan kiri gapura memiliki bentuk yang sama. Kontras dan penekanan terdapat pada garis horisontal yang mengalami perulangan yang digunakan pada seluruh gapura. Bentuk dasar yang digunakan, yaitu trapesium. Koneksi, makna, simbol, dan citra gapura memiliki kesamaan, yaitu sebagai batas territorial suatu wilayah. Pola pada gapura terdapat pola horisontal yang berulang. Skala dan proporsi pada gapura memiliki skala yang monumental yang memiliki tinggi 4,42m-11,7m, sehingga diimbangi oleh lebar gapura yang memiliki lebar 6-11,7m. Ritme, kesatuan, dan variasi terdapat pada perulangan garis horisontal yang ada pada bagian kepala, badan, dan kaki gapura. 


\section{Analisis Ciri Fisik Gapura Wringin Lawang dengan Gapura Perbatasan Kota Malang}

Pada ciri fisik, Yudoseputro (2008) mengklasifikasikan Gapura Wringin Lawang terdiri dari kepala, badan, dan kaki. Dari hasil analisis ciri fisik Gapura Wringin Lawang dengan Gapura Perbatasan Kota Malang terdapat persamaan fisik meliputi kepala, badan, dan kaki. Pada bentuk kepala terdapat bentuk atap yang terbuka. Pada bagian atap bentukan semakin mengerucut ke atas. Bagian badan gapura tidak dilengkapi ornamentasi melainkan garis horisontal yang mengalami perulangan. Pada bagian kaki terdapat kesamaan berupa dimensi yang lebih besar dan garis horisontal yang dominan (Tabel 7).

Tabel 7. Analisis Ciri Fisik Gapura

\begin{tabular}{|c|c|c|}
\hline Objek & Bagian Gapura & Analisis \\
\hline \multirow[b]{3}{*}{ Gapura Wringin Lawang } & Kepala & Bagian atap terbuka (gapura belah) dengan bentuk mengerucut ke atas. \\
\hline & Badan & Tidak dilengkapi ornamentasi melainkan garis horisontal. \\
\hline & Kaki & $\begin{array}{l}\text { Dilengkapi garis horisontal dengan bagian bawah memiliki dimensi yang } \\
\text { lebih besar. }\end{array}$ \\
\hline \multirow[b]{3}{*}{ Gapura 1} & Kepala & Atap tidak menyatu (gapura belah) dan bentuk mengerucut ke atas. \\
\hline & Badan & Menggunakan garis horisontal yang dominan \\
\hline & Kaki & Dimensi lebih besar dengan ornament garis horisontal. \\
\hline \multirow[b]{3}{*}{ Gapura 2} & Kepala & Atap terbuka dengan bentuk semakin kecil (mengerucut) \\
\hline & Badan & Dominasi garis horisontal. \\
\hline & Kaki & Dimensi lebih besar dengan ornamen garis horisontal. \\
\hline \multirow[b]{3}{*}{ Gapura 3} & Kepala & Tidak menyatu (terbuka) pada bagian atas semakin kecil (mengerucut). \\
\hline & Badan & Menggunakan garis dominan horisontal. \\
\hline & Kaki & Dimensi sama dengan badan tidak mengalami perubahan dimensi. \\
\hline \multirow[b]{3}{*}{ Gapura 4} & Kepala & Atap terpisah (gapura belah) dengan bentukan mengerucut ke atas. \\
\hline & Badan & Dominasi garis horisontal. \\
\hline & Kaki & Dimensi lebih besar dengan ornamen garis horisontal. \\
\hline
\end{tabular}

Sumber: Penulis, 2018

\section{Kesimpulan}

Luasnya kekuasaan Kerajaan Majapahit memberi dampak pada segi arsitektural tak terkecuali gapura yang merupakan salah satu prasasti Kerajaan Majapahit. Gapura merupakan penanda pintu masuk Kerajaan Majapahit, kini beralih fungsi sebagai penanda batas kawasan. Hasil analisis terdapat kesamaan aspek visual pada Gapura Wringin Lawang dengan Gapura Perbatasan di Kota Malang. Kesamaan teridentifikasi pada elemen desain, prinsip desain, dan ciri fisik gapura.

Kesamaan elemen desain teridentifikasi melalui garis, bentuk, massa, ruang, dan tekstur. Pada prinsip desain, kesamaan terdapat pada keseimbangan, kontras dan penekanan, bentuk, koneksi, makna, simbol, dan citra, pola, skala dan proporsi, ritme dan variasi. Pada bagian ciri fisik terdapat pula kemiripan yang terlihat pada bagian kepala, badan, dan kaki gapura. Studi ini membuktikan bahwa Gapura Wringin Lawang merupakan salah satu rujukan desain yang seringkali digunakan sebagai referensi rancangan gerbang kota. Perlu adanya penelitian lebih lanjut, utamanya jangkauan objek studi untuk memperdalam identifikasi kesamaan fenomena ini dengan menggunakan geometri fraktal. 


\section{Daftar Pustaka}

Alston, W. (1964). Psychoanalytic Theory and Theistic Belief' in J. Hick (ed.) Faith and the Philosophers. New York: St. Martin's Press.

Adenan, K., Budi, B. S., \& Wibowo, A. S. (2012). Karakter Visual Arsitektur Karya A.F. Aalbers di Bandung ( 1930-1946 )-Studi Kasus: Kompleks Villa's dan Woonhuizen. Jurnal Lingkungan Binaan Indonesia, 1(1).

Berry, W. (1980). Building Next to History. State: Historical society of Colorado: Good Neighbors.

Dietrich, K. (2006). Raic Syllabus Thesis Submission A Design for Architectural Education. Canada: Raic Syllabus Royal Architectural Institute of Canada.

Mohan, G. M. S. (2006). Principles of Architecture. india: Oxford University Press.

Prasodjo, T., \& Degroot, V. (2013). Magical Prambanan. PT (Persero) Taman Wisata Candi Borobudur,
Prambanan \& Ratu Boko.

Rahadian, P. (2018). Eksistensi Candi Sebagai Karya Agung Arsitektur Indonesia di Asia tenggara. (R. Emmy, Ed.). D.I Yogyakarta: PT. Kaniskus.

Rapoport, A. (1978). House Form and Culture. Milwaukee: University of Winconsin.

Sosial, K., Kholisya, U., Maya, S., \& Purnengsih, I. (2017). Karakteristik Gapura Di Kecamatan Kebakkramat Kabupaten Karanganyar Jawa Tengah (Kajian Sosial Budaya dan Ekonomi). Jurnal Desain, 04 No.02,(1957).

Suwarna. (1987). Tinjauan Selintas berbagai Jenis gapura Di Daerah Istimewa Yogyakarta (0.2 Volume). D.I Yogyakarta: Cakrawala Pendidikan.

Yudoseputro, W. (2008). Jejak-Jejak Tradisi Bahasa Rupa Indonesia Lama. Seni Visual Indonesia, 192. 